\title{
The effect of coronary artery bypass grafting on specific causes of long-term mortality in the Bypass Angioplasty Revascularization Investigation
}

David R. Holmes, Jr, MD, ${ }^{a}$ Lauren J. Kim, PhD, ${ }^{\mathrm{b}}$ Maria Mori Brooks, PhD, ${ }^{\mathrm{b}}$ Kevin E. Kip, PhD, ${ }^{\mathrm{b}}$ Hartzell V. Schaff, MD, ${ }^{\mathrm{c}}$ Katherine M. Detre, MD, DrPH, ${ }^{\mathrm{b}, *}$ and Robert L. Frye, MD, ${ }^{a}$ for the Bypass Angioplasty Revascularization Investigation (BARI) Investigators

Supplemental material is available online.
From the Divisions of Cardiovascular Diseases and Internal Medicine and Cardiovascular Surgery, Mayo Clinic College of Medicine, Rochester, Minn; and the Department of Epidemiology, University of Pittsburgh, Pittsburgh, Pa.

*Katherine M. Detre, MD, DrPH, Department of Epidemiology, University of Pittsburgh, Pittsburgh, Pennsylvania, is deceased.

This study was supported by the following grants from the National Heart, Lung, and Blood Institute: HL38493, HL38504, HL38509, HL38512, HL38514-6, HL38518, HL38524-5, HL38529, HL38532, HL38556, HL38610, HL38642, and HL42145.

Received for publication Aug 10, 2006; revisions received Jan 2, 2007; accepted for publication Jan 5, 2007.

Address for reprints: Maria Mori Brooks, $\mathrm{PhD}$, The University of Pittsburgh, Graduate School of Public Health, A530 Crabtree Hall/130 DeSoto St, Pittsburgh, PA 15261 (E-mail: mbrooks@pitt.edu).

J Thorac Cardiovasc Surg 2007;134:38-46

$0022-5223 / \$ 32.00$

Copyright (๑) 2007 by The American Association for Thoracic Surgery

doi:10.1016/j.jtcvs.2007.01.076
Objectives: We sought to examine the effect of revascularization with coronary artery bypass grafting on specific causes of death in the Bypass Angioplasty Revascularization Investigation cohort. Although the effect of coronary revascularization on long-term mortality has been previously described, there are limited data describing its effect on specific causes of death in patients with coronary artery disease. Evaluation of cause of death might help elucidate disease mechanisms and be useful for developing treatment strategies.

Methods: In the Bypass Angioplasty Revascularization Investigation randomized trial and registry, 3610 patients underwent initial revascularization with coronary artery bypass grafting or balloon angioplasty and were followed for an average of 7.7 years. Causes of all deaths were classified by an independent committee.

Results: Among 3610 revascularized patients, 2239 underwent coronary artery bypass grafting as an initial or subsequent procedure. Over 7.7 years of follow-up, $3 \%$ of all patients died of sudden cardiac death, $3 \%$ died of myocardial infarctionrelated death, $2 \%$ died of congestive heart failure and other cardiac causes, and $9 \%$ died of noncardiac causes. Coronary artery bypass grafting (vs no coronary artery bypass grafting) was associated with a significantly lower risk of sudden cardiac death (relative risk, $0.60 ; P=.01$ ) but was not significantly associated with any other causes of long-term mortality.

Conclusions: In the Bypass Angioplasty Revascularization Investigation coronary artery bypass grafting significantly decreased the risk of sudden cardiac death but not any other cause of long-term mortality. Because major risk factors for sudden cardiac death have historically favored a revascularization strategy of coronary artery bypass grafting over angioplasty, evaluation of the current practice of extending angioplasty as an alternative to coronary artery bypass grafting in similar high-risk subgroups is paramount.

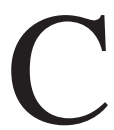
ardiovascular disease is the leading cause of mortality in Western countries. ${ }^{1}$ The specific cause of death varies and might be the result of sudden cardiac death, myocardial infarction (MI), or congestive heart failure (CHF). Although the effect of coronary revascularization on all-cause and cardiac mortality has been previously described, ${ }^{2-5}$ there are limited data on the effect of revascularization on specific causes of death in patients with coronary artery disease (CAD). Results from the Coronary Artery Surgery Study ${ }^{6}$ and other studies ${ }^{7,8}$ indicate that revascularization with coronary artery bypass grafting $(\mathrm{CABG})$ might affect specific causes of mortality, in particular sudden death. Evaluation of cause of death could help elucidate the mechanism of disease processes and have important implications 


$$
\begin{aligned}
& \text { Abbreviations and Acronyms } \\
& \begin{aligned}
\text { CABG } & =\text { coronary artery bypass grafting } \\
\text { CAD } & =\text { coronary artery disease } \\
\text { CHF } & =\text { congestive heart failure } \\
\text { CI } & =\text { confidence interval } \\
\text { ECG } & =\text { electrocardiography } \\
\text { EF } & =\text { ejection fraction } \\
\text { MI } & =\text { myocardial infarction } \\
\text { PCI } & =\text { percutaneous coronary intervention } \\
\text { PTCA } & =\text { percutaneous transluminal coronary } \\
& \text { angioplasty } \\
\text { RR } & =\text { relative risk }
\end{aligned}
\end{aligned}
$$

for developing optimal treatment strategies for improving long-term survival after coronary revascularization.

The Bypass Angioplasty Revascularization Investigation (BARI) study has cause-specific death data on 3610 patients undergoing initial revascularization with either $\mathrm{CABG}$ or percutaneous transluminal coronary angioplasty (PTCA). ${ }^{2}$ The main finding in the BARI randomized trial was a significantly lower 7-year mortality in the CABG treatment arm compared with in the PTCA treatment arm (16\% vs $19 \%$, respectively; $P=.04) .{ }^{9}$ Among patients with treated diabetes at baseline, 7-year mortality was also significantly lower in those randomized to CABG $(24 \%$ in the CABG treatment arm vs $44 \%$ in the PTCA treatment arm, $P=$ .001); however, there was no treatment difference in mortality among patients without diabetes $(14 \%$ in the CABG treatment arm vs $13 \%$ in the PTCA treatment arm, $P=.72$ ). Furthermore, the mortality difference between PTCA and CABG among patients with diabetes was due entirely to cardiac deaths. ${ }^{10}$

The purpose of this article was to investigate the effect of revascularization with $\mathrm{CABG}$ on specific causes of longterm mortality in the BARI cohort.

\section{Materials and Methods Study Design}

BARI is a multicenter clinical study designed to compare an initial revascularization strategy of CABG versus PTCA on long-term mortality in patients with multivessel coronary disease judged suitable for both procedures. The study was institutional review board approved and was sponsored by the National Heart, Lung, and Blood Institute, which was not directly involved in the data interpretation for this article. A detailed description of the study design has been published previously. ${ }^{11}$

Participants were enrolled from 18 clinical sites in the United States and Canada between August 1988 and August 1991. Eligibility criteria included clinically severe angina or evidence of ischemia requiring revascularization and angiographically documented CAD involving 2 or 3 vessels amenable to revascularization. Of the 4107 eligible patients identified, 1829 provided written informed consent to enroll in the clinical trial and be randomly assigned to receive either CABG or PTCA. Eligible patients who declined randomization were given the opportunity to participate in the BARI registry, in which the patients and their physicians selected the initial treatment but had similar follow-up schedules as the randomized patients. Two thousand ten patients provided informed consent to enroll in the BARI registry. The BARI cohort of revascularized patients is the focus of this analysis, specifically those who received their assigned revascularization treatment in the clinical trial and those who were revascularized within 3 months of enrollment in the registry.

Identical baseline data were collected for all patients, which include demographic descriptors, clinical history, 12-lead electrocardiographic (ECG) measurements, coronary angiographic measurements, angina, functional status, medications, risk factors, and quality of life. In this analysis ECG data are based on core laboratory interpretation, whereas angiographic data are based on clinical site interpretation. CABG is defined as revascularization with CABG at any time during the BARI study. Thus, patients who initially received PTCA and subsequently underwent CABG during follow-up are classified as having $\mathrm{CABG}$ in this analysis.

Follow-up data were obtained from clinic visits at 4 to 14 weeks and 1, 3, and 5 years and telephone contacts at 6 months and 2 and 4 years. After 5 years, follow-up contacts were made annually by telephone, and vital status was obtained for $98 \%$ of the patients as of September 15, 1997.

\section{Classification of Cause-of-death Outcomes}

Deaths were classified by an independent mortality and morbidity classification committee by using the following documents: death certificate; coroner's report, if available; report from the clinical site's principal investigator; surgical and catheterization laboratory reports if death occurred within 30 days of a procedure; ECG and cardiac enzyme levels measured within 24 hours of death; and in-hospital data ascertained from medical records. Each death was reviewed independently by 2 members of the mortality and morbidity classification committee and classified into one of the following primary classifications: direct or contributory cardiac, atherosclerosis-related noncardiac, noncardiac medical (eg, cancer and pulmonary disease), noncardiac trauma, accident, suicide, other, unknown, and unclassifiable causes. ${ }^{11}$ Disagreements between reviewers on the primary cause of death were resolved by full committee consensus.

Deaths determined to be of cardiac origin received one of the following secondary classifications: sudden death, death secondary to MI, CHF, cardiogenic shock, unwitnessed beyond 1 hour, and other documented cardiac causes. Agreement between the 2 reviewers on the secondary classifications was not required. If reviewers assigned different secondary causes to the same patient death, the following hierarchy was applied to determine death classification for this analysis: unwitnessed beyond 1 hour was preferred over MI death, which was preferred over sudden death, which was preferred over CHF, which was preferred over other cardiac causes. By using these classifications, the following 4 end points were defined for the purpose of this analysis: (1) sudden cardiac death includes deaths within 1 hour of the onset of cardiac symptoms and deaths unwitnessed beyond 1 hour; (2) MI death includes deaths within 30 days of documented or probable MI and deaths resulting from cardiogenic shock; (3) CHF and other car- 
diac death includes deaths as a result of $\mathrm{CHF}$ and all other documented cardiac causes; and (4) noncardiac death includes deaths resulting from atherosclerosis, medical- and trauma-related noncardiac causes, accidents, suicides, and other, unknown, and unclassifiable causes.

\section{Statistical Analyses}

Baseline characteristics are presented by vital status and by cause of death. Statistical comparisons were made between groups defined by the 4 mutually exclusive causes of death (alive patients excluded). $\chi^{2}$ Tests were used to compare categoric variables, and Wilcoxon nonparametric tests were used to compare continuous variables.

For all time-to-event analyses, the date of the initial revascularization procedure was considered time zero, and patients remained in the no-CABG group until the time that they received a $\mathrm{CABG}$, at which point they joined the CABG group. Cumulative mortality rates in the $\mathrm{CABG}$ and no-CABG groups were estimated by using the transient-state method ${ }^{12}$ and compared by using the log-rank test.

Multivariate analysis was conducted with Wei-Lin-Weissfeld competing-risks regression, ${ }^{13}$ an extension of the traditional Cox proportional hazards regression that allows multiple competing outcomes to be modeled simultaneously. Patients were considered to be at risk for the 4 cause-specific mortality outcomes until the time of either censoring or death. Patients who died were considered to have had an event for the specific cause of their death and censored for the other 3 outcomes at the time of death. An initial competing-risks model was constructed to estimate the unadjusted effect of CABG on cause of death and to test for departures from the proportional hazards assumption. A multivariate model was built by allowing baseline predictors of mortality ${ }^{14}$ to enter by using forward stepwise selection (entry criterion, $P<.05$ ). The time-dependent CABG variable was then added to the model, and covariates with a $P$ value of greater than .01 were removed by using backward selection. Missing values ( $<3 \%$ for any variable) for clinical history variables included in the final multivariate model were set to the mean value for continuous variables and zero for binary variables. Differential effects of CABG on the 4 causespecific mortality outcomes were tested in the multivariate model. Statistical interactions between CABG and diabetes status on each cause of death were also tested. In the presence of any significant interactions, separate multivariate models were constructed for patients with diabetes and for those without diabetes. Lastly, standard Cox regression was used to estimate the independent effect of CABG on all-cause mortality. ${ }^{15}$

Estimates of relative risk (RR), 95\% confidence intervals (CIs), and $P$ values are reported. All analyses were performed with SAS version 8.2 (SAS, Cary, NC).

\section{Results}

Three thousand six hundred ten BARI participants underwent coronary revascularization and were followed for an average of 7.7 years. Patients receiving CABG included those who received $\mathrm{CABG}$ as the initial revascularization ( $\mathrm{n}$ $=1517$ ) and those who received PTCA as the initial procedure and subsequently crossed over to CABG $(\mathrm{n}=722)$,
$52 \%$ of which occurred within 6 months of initial treatment with PTCA. There were 1371 patients who received only PTCA (no CABG) during 7.5 years. At the end of followup, $83 \%$ of patients $(\mathrm{n}=2989)$ were alive, and $17 \%(\mathrm{n}=$ 621) had died (Figure E1). Three percent $(n=107)$ of patients died of sudden cardiac death, 3\% $(\mathrm{n}=109)$ died of MI, $2 \%(n=68)$ died of CHF and other cardiac causes, and $9 \%(\mathrm{n}=337)$ died of noncardiac causes. Of all deaths, $17 \%$ were attributed to sudden cardiac death, $18 \%$ to $\mathrm{MI}, 11 \%$ to $\mathrm{CHF}$ and other cardiac causes, and $54 \%$ to noncardiac causes.

Characteristics at study entry are presented in Table 1. Among patients who died, mean age at baseline, presence of diabetes, history of MI, CHF, angina duration of at least 1 year, ST-segment depression, and ejection fraction (EF) of less than $50 \%$ differed significantly by cause of death. Those patients who died suddenly were younger than patients who died of other causes. Compared with surviving patients, those who died from sudden cardiac death more frequently had EFs of less than $50 \%$, diabetes, prior MI, unstable angina, triple-vessel disease, and abnormalities on baseline ECG.

\section{Unadjusted Effect of CABG on Causes of Death}

Unadjusted mortality rates were 17\% (251/1517) among patients who underwent $\mathrm{CABG}$ as the initial revascularization, $13 \%$ (97/722) among patients who received CABG as a subsequent procedure, and 20\% (273/1371) among patients who never received CABG. On the basis of transientstate Kaplan-Meier curves (Figure 1), noncardiac death rates among patients who underwent $\mathrm{CABG}$ and those who did not were similar throughout follow-up and were $9.7 \%$ and $9.9 \%$, respectively $(P=.84)$ at 7.5 years. Cardiac mortality in the $\mathrm{CABG}$ and no-CABG groups were similar over time, with an early preponderance of events and a gradual increase over the remaining follow-up period. Seven and a half years after initial revascularization, cardiac death rates in the $\mathrm{CABG}$ and no-CABG groups were $7.3 \%$ and $8.6 \%$, respectively $(P=.93)$.

Transient-state Kaplan-Meier estimates of 7.5-year cause-specific mortality rates are shown in Figure 2. Patients who underwent CABG had a significantly lower incidence of sudden death $(2.4 \%$ vs $3.9 \%, P=.01)$ but similar rates of deaths resulting from MI $(3.2 \%$ vs $3.1 \%$, $P=.64), \mathrm{CHF}$ and other cardiac causes (1.9\% vs $1.9 \%$, $P=.59)$, and noncardiac causes (9.7\% vs $9.9 \%, P=$ .84). Unadjusted competing-risks analysis demonstrated consistent results. Revascularization with $\mathrm{CABG}$ was associated with a significantly lower risk of sudden cardiac death (RR, 0.62; 95\% CI, 0.42-0.91; $P=.01)$ but was not associated with the other causes of death individually (MI: RR, 1.10; 95\% CI, 0.75-1.61; $P=.63$; $\mathrm{CHF}$ and other cardiac causes: RR, 1.14; $95 \% \mathrm{CI}, 0.70-$ 
TABLE 1. Baseline characteristics by vital status and cause of death

\begin{tabular}{|c|c|c|c|c|c|c|}
\hline & & & Dead (ce & death) & & \\
\hline & $\begin{array}{c}\text { Alive } \\
\text { (n= 2989) }\end{array}$ & $\begin{array}{l}\text { Sudden death } \\
\qquad(\mathrm{n}=107)\end{array}$ & $\begin{array}{c}\text { MI } \\
(n=109)\end{array}$ & $\begin{array}{c}\text { CHF/other } \\
\text { cardiac } \\
(n=68)\end{array}$ & $\begin{array}{c}\text { Noncardiac } \\
(n=337)\end{array}$ & $\begin{array}{c}P \\
\text { value* }^{*}\end{array}$ \\
\hline Demographic profile & & & & & & \\
\hline Age (y) & $61 \pm 10$ & $62 \pm 9$ & $64 \pm 10$ & $67 \pm 9$ & $66 \pm 9$ & $<.01$ \\
\hline Male sex & 75 & 77 & 63 & 60 & 68 & .09 \\
\hline White race & 93 & 82 & 89 & 85 & 89 & .31 \\
\hline Black race & 4 & 12 & 10 & 10 & 8 & \\
\hline Post-high school education & 36 & 28 & 26 & 25 & 29 & .33 \\
\hline Medical history & & & & & & \\
\hline Treated diabetes & 15 & 31 & 36 & 47 & 30 & .04 \\
\hline $\mathrm{MI}$ & 51 & 65 & 64 & 62 & 51 & .01 \\
\hline $\mathrm{CHF}$ & 5 & 14 & 23 & 25 & 14 & .03 \\
\hline Peripheral vascular disease & 13 & 21 & 26 & 29 & 29 & .40 \\
\hline Hypertension & 46 & 55 & 64 & 69 & 58 & .20 \\
\hline Renal dysfunction & 1 & 7 & 6 & 12 & 5 & .21 \\
\hline Malignancy & 4 & 7 & 6 & 10 & 12 & .16 \\
\hline Clinical profile & & & & & & \\
\hline Former smoker & 46 & 50 & 40 & 44 & 47 & .52 \\
\hline Current smoker & 23 & 25 & 27 & 21 & 26 & \\
\hline Stable angina class 1 or 2 & 16 & 10 & 13 & 12 & 13 & .27 \\
\hline Stable angina class 3 or 4 & 15 & 9 & 16 & 24 & 15 & \\
\hline Unstable angina/non-0 MI & 68 & 80 & 72 & 65 & 71 & \\
\hline Angina duration $\geq 1 \mathrm{y}$ & 39 & 34 & 55 & 43 & 49 & .01 \\
\hline Major Q-waves & 16 & 23 & 25 & 22 & 23 & .96 \\
\hline ST depression & 5 & 12 & 8 & 21 & 6 & $<.01$ \\
\hline Major ECG abnormality & 40 & 54 & 52 & 54 & 52 & .97 \\
\hline Angiographic profile & & & & & & \\
\hline Triple-vessel disease & 37 & 49 & 46 & 49 & 40 & .28 \\
\hline Proximal LAD disease & 38 & 38 & 43 & 25 & 40 & .12 \\
\hline Ejection fraction $<50 \% \dagger$ & 14 & 28 & 24 & 34 & 20 & .02 \\
\hline Left-sided/mixed dominance & 14 & 23 & 26 & 12 & 17 & .06 \\
\hline
\end{tabular}

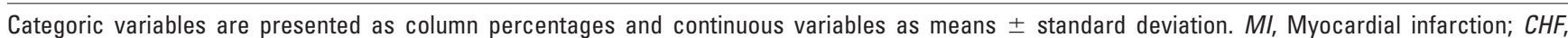
congestive heart failure; $E C G$, electrocardiographic; $L A D$, left anterior descending coronary artery. ${ }^{*} P$ values compare 4 causes of death among patients who died. †Ejection fraction data are missing for 462 patients.

$1.87 ; P=.59$; noncardiac causes: RR, 0.98; $95 \% \mathrm{CI}$, $0.79-1.22 ; P=.84)$ or these 3 causes of death combined (RR, $1.02 ; 95 \%$ CI, 0.86-1.22; $P=.80$ ).

\section{Multivariate Analyses}

Adjusted mortality estimates are presented in Table 2. Revascularization with CABG did not significantly affect allcause mortality (RR, 0.90; 95\% CI, 0.77-1.06; $P=.19$ ). CABG was associated with a significantly lower risk of sudden cardiac death (RR, 0.60; 95\% CI, 0.41-0.88; $P=$ $.01)$ but was not associated with other causes of death individually or combined (RR, $0.98 ; 95 \% \mathrm{CI}, 0.82-1.17 ; P$ $=.83$ ). Moreover, the effect of $\mathrm{CABG}$ on sudden cardiac death was significantly different than the effect of CABG on all other causes of death combined (RR, 0.60 vs $0.98 ; P=$ $.02)$. The multivariate model also revealed a statistically significant interaction between $\mathrm{CABG}$ and diabetes status for death caused by MI (test of interaction, $P=.04$ ) but not any of the other causes (sudden death, $P=.92$; CHF/other cardiac causes, $P=.19$; noncardiac causes, $P=.53$ ). Therefore the adjusted effect of $\mathrm{CABG}$ on cause-specific mortality was examined separately for nondiabetic and diabetic patients (Table 2).

Among patients without diabetes, revascularization with CABG significantly decreased the risk of sudden cardiac death (RR, 0.61; 95\% CI, 0.38-0.97; $P=.04$ ) but did not significantly affect any other specific causes of death or overall mortality. In patients with diabetes, CABG was associated with a 32\% lower risk of long-term mortality, and a trend toward a protective effect on sudden death (RR, 0.55; 95\% CI, $0.28-$ $1.10 ; P=.09)$ and death caused by MI (RR, 0.54; 95\% CI, $0.28-1.02 ; P=.06)$ was observed. Revascularization with 

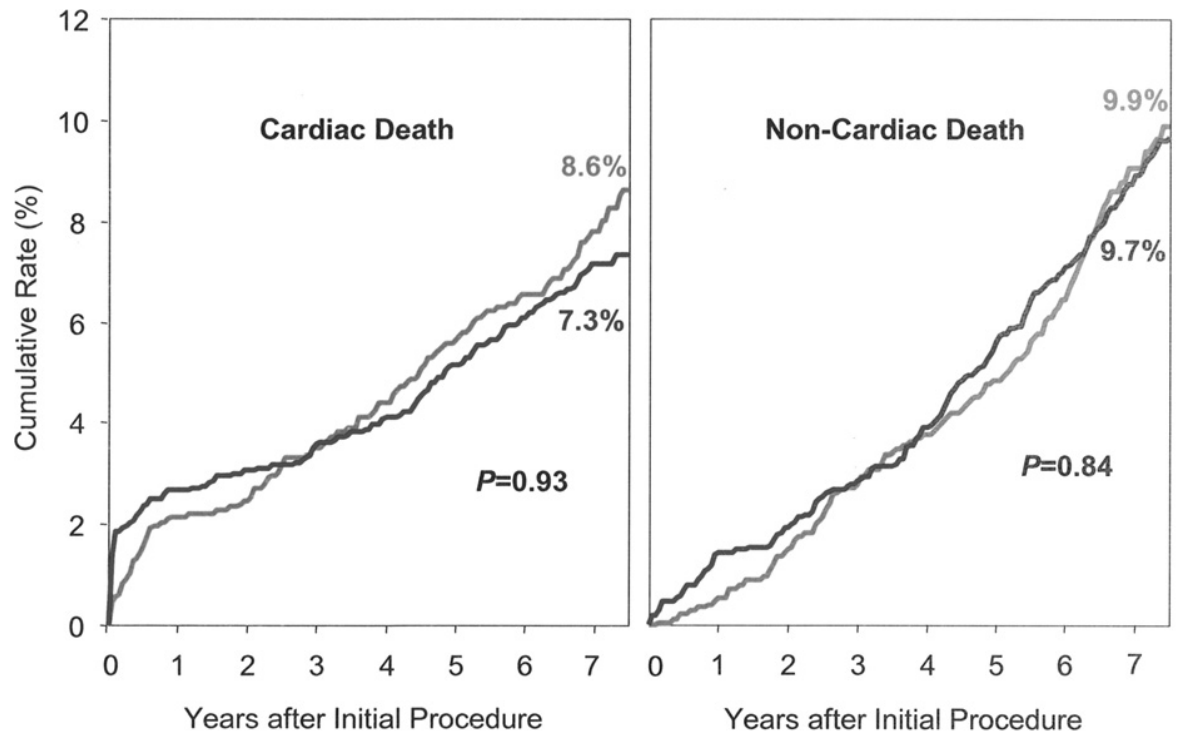

Figure 1. Kaplan-Meier curves for cardiac and noncardiac death by coronary artery bypass grafting (CABG) status.
CABG was not associated with $\mathrm{CHF}$-related or noncardiac mortality among diabetic patients.

\section{Further Examination of Sudden Cardiac and MI-} related Deaths

The effect of CABG on sudden death and MI-related death over time stratified by diabetes status is shown in Figures 3 and 4. Among patients without diabetes, the cumulative sudden death rate curves diverged steadily over time and,
7.5 years after initial revascularization, were significantly lower in patients who underwent $\mathrm{CABG}$ versus those who did not $(2.0 \%$ vs $3.3 \%, P=.04)$. A similar protective effect was observed in patients with diabetes, with sudden death rates of $4.4 \%$ and $7.7 \%(P=.08)$ at 7.5 years in the CABG and no-CABG groups, respectively. In patients without diabetes, MI-related mortality occurred more frequently in the CABG group in the first month; however, during 7.5 years of follow-up, the cumulative rates converged such that

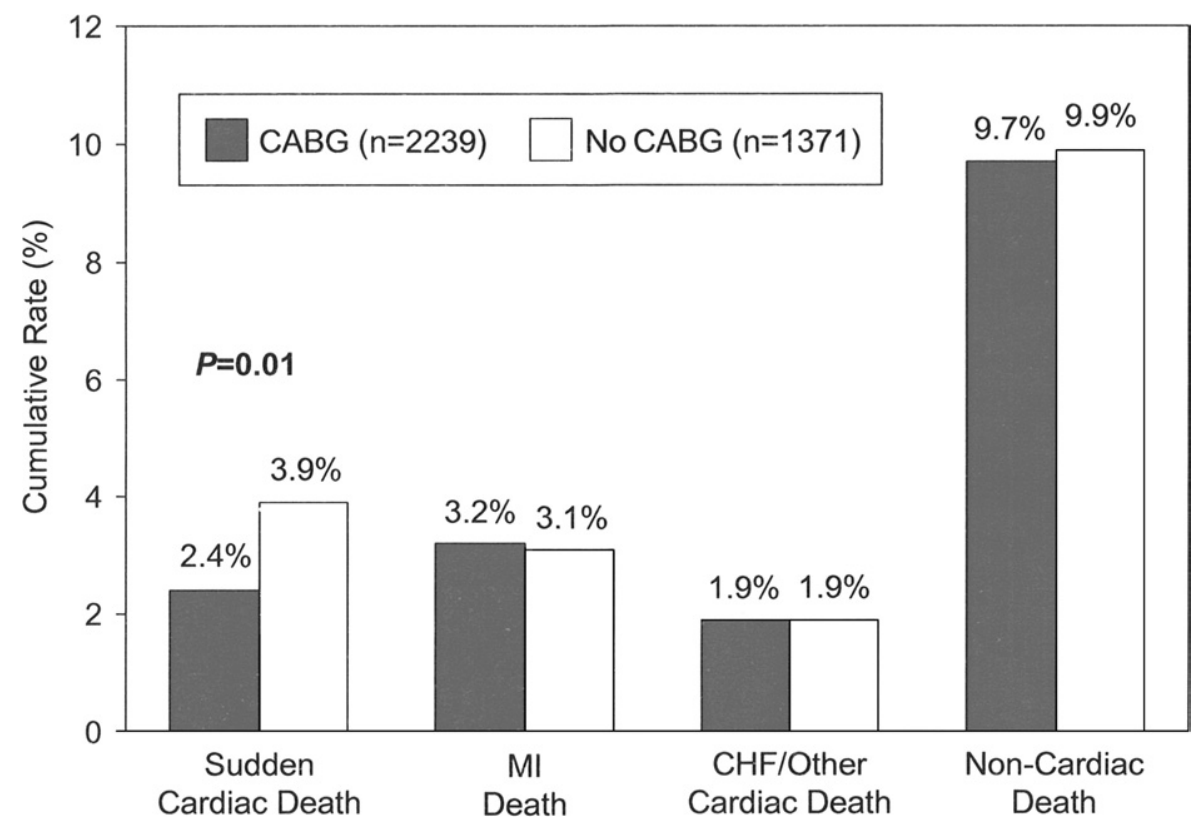

Figure 2. Cumulative rates at 7.5 years for specific causes of death by coronary artery bypass grafting (CABG) status. MI, Myocardial infarction; CHF, congestive heart failure.

42 The Journal of Thoracic and Cardiovascular Surgery • July 2007 
TABLE 2. Relative risk associated with coronary artery bypass grafting for overall and specific causes of long-term mortality

\begin{tabular}{|c|c|c|c|c|c|c|c|c|c|c|c|c|}
\hline & \multicolumn{4}{|c|}{ All patients $(n=3610)$} & \multicolumn{4}{|c|}{ No diabetes $(\mathrm{n}=2968)$} & \multicolumn{4}{|c|}{ Diabetes $(n=642)$} \\
\hline & $\begin{array}{l}\text { No. of } \\
\text { events }\end{array}$ & $\mathbf{R R}^{*}$ & $95 \%$ CI & $\begin{array}{c}P \\
\text { value }\end{array}$ & $\begin{array}{l}\text { No. of } \\
\text { events }\end{array}$ & $\mathbf{R R}^{*}$ & $95 \%$ CI & $\begin{array}{c}P \\
\text { value }\end{array}$ & $\begin{array}{l}\text { No. of } \\
\text { events }\end{array}$ & $\mathbf{R R}^{*}$ & $95 \%$ Cl & $\begin{array}{c}P \\
\text { value }\end{array}$ \\
\hline \multicolumn{13}{|c|}{ Effect of CABG (vs no CABG) on: } \\
\hline All-cause mortality & 621 & 0.90 & $0.77-1.06$ & .19 & 416 & 1.01 & $0.83-1.23$ & .94 & 205 & 0.68 & $0.52-0.90$ & .01 \\
\hline Sudden cardiac death† & 107 & 0.60 & $0.41-0.88$ & .01 & 74 & 0.61 & $0.38-0.97$ & .04 & 33 & 0.55 & $0.28-1.10$ & .09 \\
\hline MI death $\ddagger$ & 109 & 1.06 & $0.72-1.56$ & .76 & 70 & 1.51 & $0.92-2.46$ & .10 & 39 & 0.54 & $0.28-1.02$ & .06 \\
\hline CHF/other cardiac death & 68 & 1.10 & $0.67-1.79$ & .72 & 36 & 1.49 & $0.74-2.99$ & .26 & 32 & 0.69 & $0.34-1.39$ & .30 \\
\hline Noncardiac death & 337 & 0.93 & $0.75-1.16$ & .54 & 236 & 0.99 & $0.77-1.29$ & .96 & 101 & 0.80 & $0.54-1.19$ & .27 \\
\hline
\end{tabular}

$R R$, Relative risk; $95 \% \mathrm{Cl}, 95 \%$ confidence interval; $C A B G$, coronary artery bypass grafting; $M I$, myocardial infarction; $C H F$, congestive heart failure. ${ }^{*}$ Adjusted for diabetes, age, sex, race, smoking, congestive heart failure, hypertension, major electrocardiographic abnormality, peripheral vascular disease, renal dysfunction, left/mixed dominance, ejection fraction, and malignancy. †Among all patients, the effect of coronary artery bypass grafting on sudden cardiac death was significantly different than on all other causes of death combined (test of interaction, $P=.02$ ). $\ddagger$ The effect of coronary artery bypass grafting on myocardial infarction-related death was significantly different in nondiabetic and diabetic patients (test of interaction, $P=.04$ ).

the MI-related death rate was $2.7 \%$ in the $\mathrm{CABG}$ group and $2.0 \%$ in the no-CABG group $(P=.10)$. In contrast, among patients with diabetes, the MI-related death rate was slightly higher in the $\mathrm{CABG}$ group during the first 2 years, but by 7.5 years, the cumulative MI-related death rate was significantly lower in patients who underwent $\mathrm{CABG}$ compared with the rate in those who did not $(5.4 \%$ vs $10.2 \%, P=.04)$.

\section{Discussion}

CABG had differential effects on various causes of longterm mortality in the BARI cohort of revascularized patients. Revascularization with CABG significantly decreased the risk of sudden cardiac death but did not affect other causes of death. Furthermore, the protective effect of CABG against sudden death was observed in patients regardless of diabetes status.

Why might CABG reduce the risk of sudden cardiac death? Although the mechanism of sudden death in the setting of CAD is complex, it commonly occurs secondary to ventricular tachyarrhythmia ${ }^{16,17}$ (which often degenerates into ventricular fibrillation ${ }^{18}$ ) triggered by myocardial ischemia. ${ }^{19}$ In general, patients receiving CABG are more completely revascularized and have the advantage of a greater relief of myocardial jeopardy than those undergoing percutaneous intervention, which targets a more limited extent of a given coronary artery. ${ }^{20}$ Although this approach to percutaneous coronary intervention (PCI) does not appear to compromise overall survival, as per BARI in those without treated diabetes, the current study indicates that PTCA, as performed between 1988 and 1991, left patients at risk for sudden death in contrast to revascularization with CABG. Thus, we suggest that patients in BARI who received $\mathrm{CABG}$ had greater and more durable protection against MI, which preferentially protected against acute environmental events that might heighten susceptibility to ventricular arrhythmia. This is further supported by the CABG-Patch trial, which indicated that bypass surgery was protective against sudden death, such that cardiac defibrillator implantation did not confer additional benefit. ${ }^{21}$

Our results might have important clinical implications for guiding CAD treatment strategies. Specifically, CABG might be the preferred method of revascularization in patients who are identified as having an increased risk of sudden cardiac death because of extensive CAD, ${ }^{6,22}$ a history of ventricular arrhythmia, ${ }^{23}$ ECG abnormalities, and impaired left ventricular function. ${ }^{24}$ Consistent with prior studies, patients who died suddenly in BARI were more likely to have EFs of less than 50\%, diabetes, history of MI, triple-vessel disease, unstable angina, and abnormalities on resting ECG. If PCI is the intervention ultimately chosen in this high-risk subset, a more complete revascularization might be wise. Prior studies in the Coronary Artery Surgery Study emphasized the importance of complete surgical revascularization in patients with decreased left ventricular function. Patients who are not suitable candidates for bypass surgery might benefit from added measures to prevent sudden death, such as prophylactic use of an implantable cardiac defibrillator, which has been shown to substantially improve survival in the CAD population by preventing sudden death. ${ }^{25}$

Of note, PTCA in BARI preceded the routine use of both bare-metal and drug-eluting stents, and similarly, CABG has continually progressed with improved perioperative management, more frequent use of arterial grafting, and improved techniques with minimally invasive and off-pump operations as options. ${ }^{26,27}$ In the context of these developments, are the BARI results relevant? Yes. As described above, the subset of patients who benefited most from CABG were those at high risk of sudden cardiac death as characterized by extensive $\mathrm{CAD}$, decreased left ventricular function, and abnormalities on the resting electrocardiogram, for example. By way of analogy, PCI is currently 


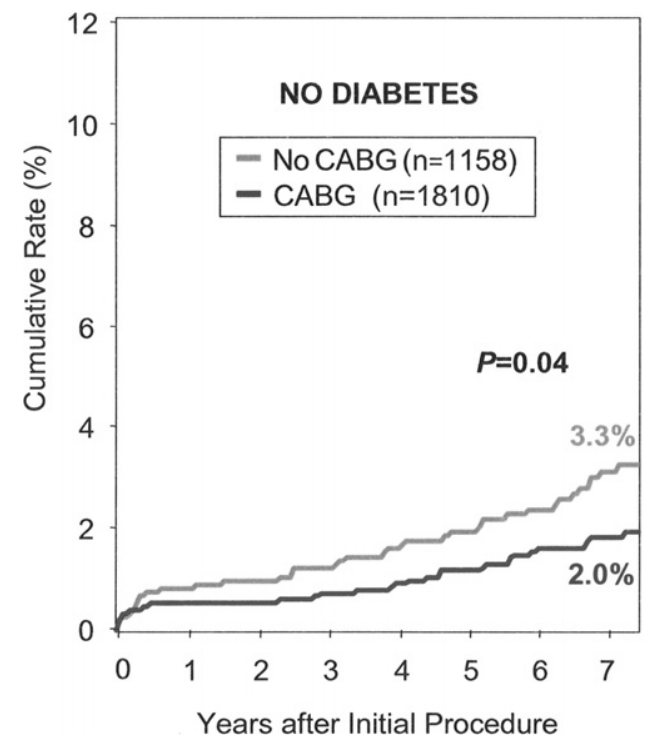

challenging $\mathrm{CABG}$ as an alternative for revascularization of high-risk patients with triple-vessel disease or left main disease, domains historically reserved for CABG. Whether current methods of PCI will eliminate or minimize the historical advantage of CABG in selected high-risk subsets is under study in several current large randomized trials. To this end, our data corroborate the need for rigorous evaluation of revascularization strategy of very high-risk patients, in particular those at high risk of sudden cardiac death.

Multivariate analysis of cause-specific mortality also revealed that the effect of CABG on MI-related death was modified by diabetes status. For the relative effect of bypass surgery on MI-related mortality, the stratified models dem- onstrated a trend toward an increased risk in patients without diabetes and a decreased risk in those with diabetes. Furthermore, the effect of CABG on MI-related death differed significantly in the presence versus absence of diabetes. This is consistent with the previous report by Detre and colleagues $^{28}$ that demonstrated that among revascularized patients who have an MI, CABG offered greater protection against long-term mortality in diabetic patients compared with nondiabetic patients.

The purpose of this analysis was to evaluate the effect of receiving $\mathrm{CABG}$ on various causes of mortality and not to evaluate the strategy of initial revascularization with CABG versus PTCA, which is best accomplished in an intent-to-
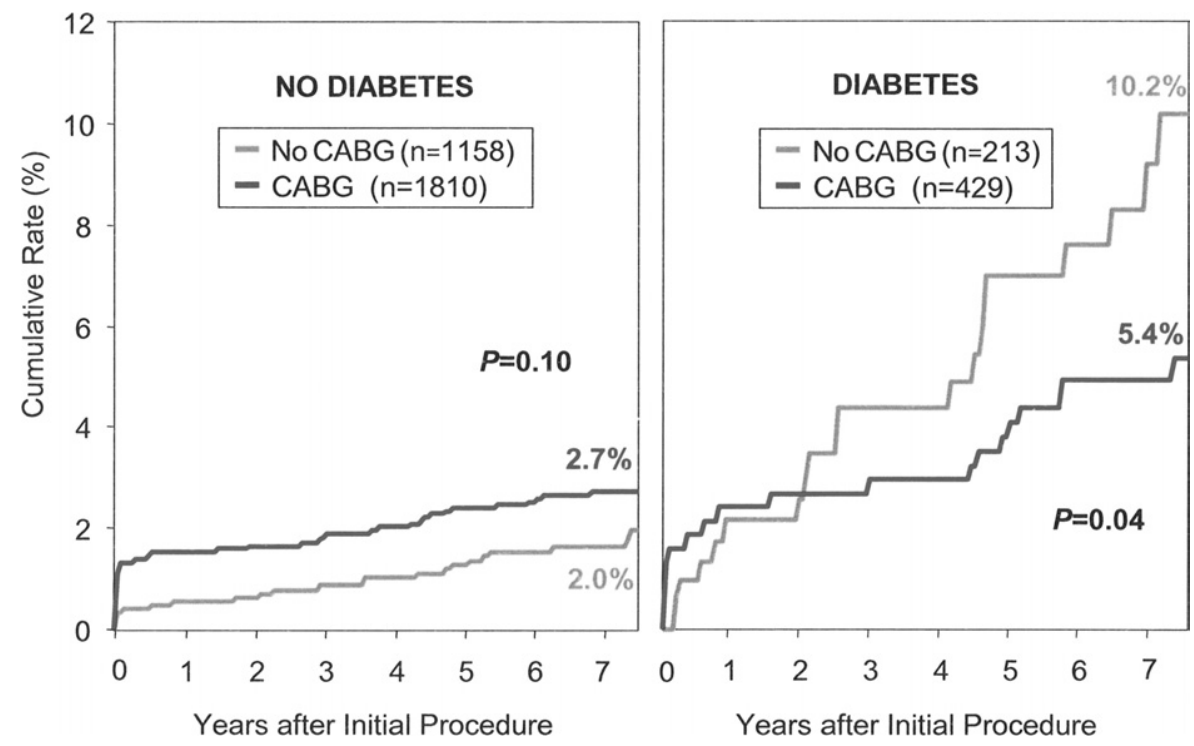

Figure 4. Kaplan-Meier curves for myocardial infarction-related death comparing coronary artery bypass grafting (CABG) versus no CABG stratified by diabetes status.

44 The Journal of Thoracic and Cardiovascular Surgery • July 2007 
treat analysis of a randomized clinical trial. Because BARI registry patients met every eligibility criteria for the randomized trial except a willingness to be randomly assigned to treatment, our purpose was best served by including both the randomized and registry cohorts in this analysis and by considering treatment with $\mathrm{CABG}$ at any time during the BARI study as our key covariate. The same patient sample and methodology were used in the BARI report by Detre and colleagues ${ }^{28}$ to evaluate the effect of CABG on survival after an MI.

All-cause mortality is a common end point in clinical studies because death, regardless of its cause, is a critical and meaningful outcome, especially when evaluating treatments designed to prolong survival. From a methodologic perspective, clearly defined end points are more easily verified, and the data are more often complete. Despite such advantages, important implications of the disease process and treatment effect might be missed by ignoring causespecific death. Holmes and associates ${ }^{4}$ reported that the ratio of cardiac to noncardiac deaths tends to decrease as patients age within a study cohort and as follow-up time increases. A preponderance of noncardiac deaths might obscure accurate interpretation of studies investigating long-term treatment effects, particularly in an aging patient population.

This study has the limitations of an observational study, as well as the difficulty of establishing the actual cause of death. A strength of the BARI study, however, is the manner in which cause of death was determined. An independent morbidity and mortality committee comprised of cardiologists was included in the original BARI design, and the initial 5-year results showing a survival benefit with $\mathrm{CABG}$ in patients with diabetes was greatly enhanced by determining that the difference was entirely due to cardiac mortality.

\section{Conclusions}

Evaluation of cause-specific mortality provided additional information beyond standard analysis of all-cause or cardiac mortality. In BARI, CABG had different effects on specific causes of long-term mortality in patients with multivessel CAD. Revascularization with CABG significantly decreased the risk of sudden cardiac death, regardless of diabetes status, while not significantly affecting the risk of other causes of death. Evaluation of specific causes of death provides insights that might be useful for guiding treatment selection and developing strategies to improve long-term survival after coronary revascularization.

\section{References}

1. Murray CJ, Lopez AD. Mortality by cause for eight regions of the world: Global Burden of Disease Study. Lancet. 1997;349:1269-76.
2. The Bypass Angioplasty Revascularization Investigation (BARI) Investigators. Comparison of coronary bypass surgery with angioplasty in patients with multivessel disease. N Engl J Med. 1996;335:217-25.

3 . Coronary angioplasty versus coronary artery bypass surgery: the Randomized Intervention Treatment of Angina (RITA) trial. Lancet. 1993; 341:573-80.

4. Holmes DR Jr, Kip KE, Kelsey SF, Detre KM, Rosen AD. Cause of death analysis in the NHLBI PTCA Registry: results and considerations for evaluating long-term survival after coronary interventions. J Am Coll Cardiol. 1997;30:881-7.

5. King SB 3rd, Kosinski AS, Guyton RA, Lembo NJ, Weintraub WS. Eight-year mortality in the Emory Angioplasty versus Surgery Trial (EAST). J Am Coll Cardiol. 2000;35:1116-21.

6. Holmes DR Jr, Davis KB, Mock MB, et al. The effect of medical and surgical treatment on subsequent sudden cardiac death in patients with coronary artery disease: a report from the Coronary Artery Surgery Study. Circulation. 1986;73:1254-63.

7. Hammermeister KE, DeRouen TA, Murray JA, Dodge HT. Effect of aortocoronary saphenous vein bypass grafting on death and sudden death. Comparison of nonrandomized medically and surgically treated cohorts with comparable coronary disease and left ventricular function. Am J Cardiol. 1977;39:925-34.

8. Vismara LA, Miller RR, Price JE, Karem R, DeMaria AN, Mason DT. Improved longevity due to reduction of sudden death by aortocoronary bypass in coronary atherosclerosis. Am J Cardiol. 1977;39:919-24.

9. Seven-year outcome in the Bypass Angioplasty Revascularization Investigation (BARI) by treatment and diabetic status. J Am Coll Cardiol. 2000;35:1122-9.

10. Influence of diabetes on 5-year mortality and morbidity in a randomized trial comparing CABG and PTCA in patients with multivessel disease: the Bypass Angioplasty Revascularization Investigation (BARI). Circulation. 1997;96:1761-9.

11. Protocol for the Bypass Angioplasty Revascularization Investigation. Circulation. 1991;84:V1-27.

12. Mantel N, Byar DP. Evaluation of response-time data involving transient states: an illustration using heart-transplant data. J Am Stat Assoc. 1974;69:81-6.

13. Wei LJ, Lin DY, Weissfeld L. Regression analysis of multivariate incomplete failure time data by modeling marginal distributions. $\mathrm{J} \mathrm{Am}$ Stat Assoc. 1989;84:1065-73.

14. Brooks MM, Jones RH, Bach RG, et al. Predictors of mortality and mortality from cardiac causes in the bypass angioplasty revascularization investigation (BARI) randomized trial and registry. Circulation. 2000;101:2682-9.

15. Cox DR. Regression models and life-tables. J R Stat Soc B. 1972;34: 187-220.

16. Kempf FC Jr, Josephson ME. Cardiac arrest recorded on ambulatory electrocardiograms. Am J Cardiol. 1984;53:1577-82.

17. Liberthson RR, Nagel EL, Hirschman JC, Nussenfeld SR. Prehospital ventricular defibrillation. Prognosis and follow-up course. $N$ Engl J Med. 1974;291:317-21.

18. Bayes de Luna A, Coumel P, Leclercq JF. Ambulatory sudden cardiac death: mechanisms of production of fatal arrhythmia on the basis of data from 157 cases. Am Heart J. 1989;117:151-9.

19. Davies MJ, Thomas A. Thrombosis and acute coronary-artery lesions in sudden cardiac ischemic death. $N$ Engl J Med. 1984;310:1137-40.

20. Alderman EL, Kip KE, Whitlow PL, et al. Native coronary disease progression exceeds failed revascularization as cause of angina after five years in the Bypass Angioplasty Revascularization Investigation (BARI). J Am Coll Cardiol. 2004;44:766-74.

21. Bigger JT, The Coronary Artery Bypass Graft Patch Trial I. Prophylactic use of implanted cardiac defibrillators in patients at high risk for ventricular arrhythmias after coronary-artery bypass graft surgery. N Engl J Med. 1997;337:1569-75.

22. Kannel WB, Doyle JT, McNamara PM, Quickenton P, Gordon T. Precursors of sudden coronary death. Factors related to the incidence of sudden death. Circulation. 1975;51:606-13.

23. Chiang BN, Perlman LV, Ostrander LD Jr, Epstein FH. Relationship of premature systoles to coronary heart disease and sudden death in the Tecumseh epidemiologic study. Ann Intern Med. 1969;70:1159-66. 
24. Sanz G, Castaner A, Betriu A, et al. Determinants of prognosis in survivors of myocardial infarction: a prospective clinical angiographic study. N Engl J Med. 1982;306:1065-70.

25. Moss AJ, Hall WJ, Cannom DS, et al. Improved survival with an implanted defibrillator in patients with coronary disease at high risk for ventricular arrhythmia. Multicenter Automatic Defibrillator Implantation Trial Investigators. N Engl J Med. 1996;335:1933-40.

26. Nishida H, Tomizawa Y, Endo M, Kurosawa H. Survival benefit of exclusive use of in situ arterial conduits over combined use of arterial and vein grafts for multiple coronary artery bypass grafting. Circulation. 2005;112(suppl):I299-303.
27. Ferguson TB Jr, Hammill BG, Peterson ED, DeLong ER, Grover FL. A decade of change-risk profiles and outcomes for isolated coronary artery bypass grafting procedures, 1990-1999: a report from the STS National Database Committee and the Duke Clinical Research Institute. Society of Thoracic Surgeons. Ann Thorac Surg. 2002;73:480-90

28. Detre KM, Lombardero MS, Brooks MM, et al. The effect of previous coronary artery bypass surgery on the prognosis of patients with diabetes who have acute myocardial infarction. Bypass Angioplasty Revascularization Investigation Investigators. N Engl J Med. 2000; 342:989-97.

\section{Interactive eLearning Activities http://learning.ctsnet.org}

The Joint Council on Thoracic Surgery Education was pleased to introduce a series of unique eLearning activities to CTSNet users at the AATS annual meeting in Philadelphia. Sponsored by several cardiothoracic surgical groups, this exciting new educational tool contains narrated videos of actual surgical procedures followed by a series of questions and an evaluation to earn Continuing Medical Education credit.

* Diagnosis and Management of Complications of Mitral Valve Repair

* Off Pump Coronary Artery Bypass

* OPCAB Debriefing

* Pediatric Cardiopulmonary Bypass Emergency Situations

\section{Experience these new educational tools today and provide us with your feedback. Go to: http://learning.ctsnet.org}

William E. Baumgartner, Chair

Joint Council on Thoracic Surgery Education

Sponsored By: American Association for Thoracic Surgery

The Society of Thoracic Surgeons

European Association for Cardio-Thoracic Surgery

Children's Memorial Hospital 

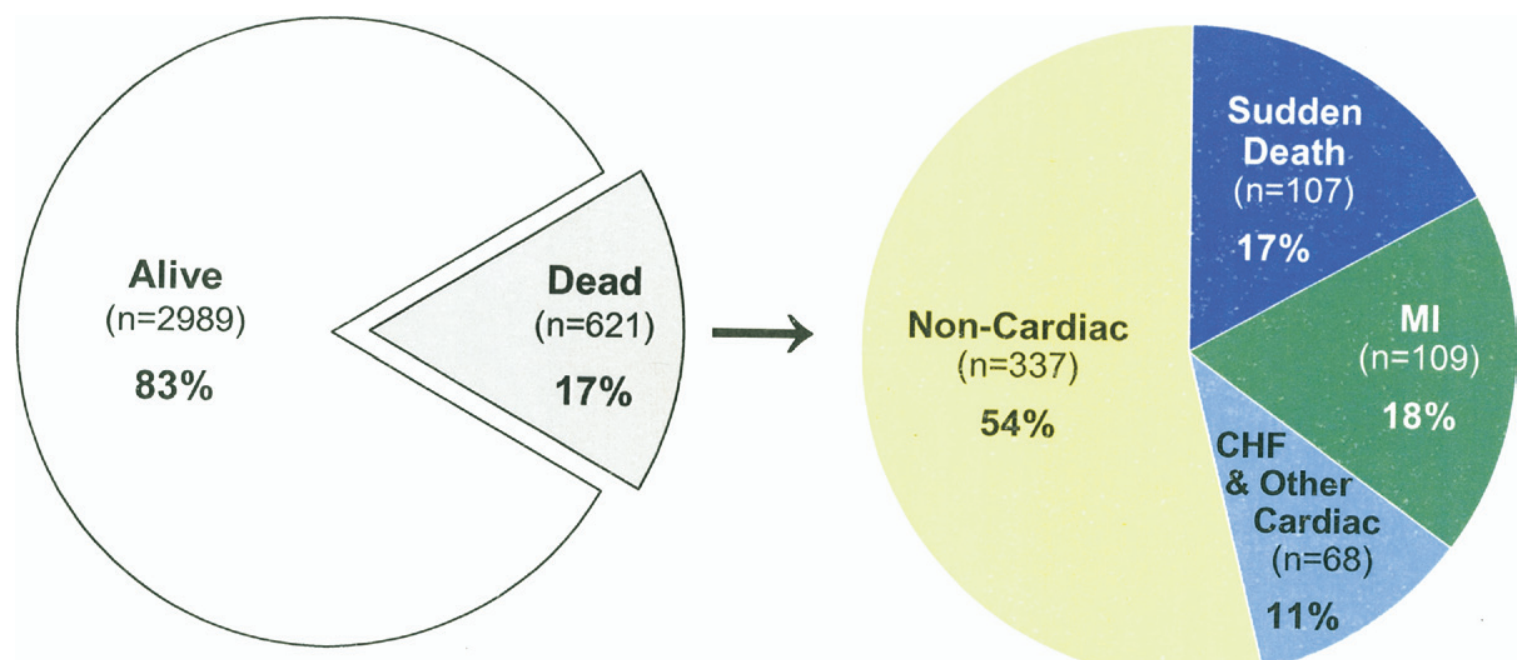

Figure E1. Vital status and cause of death (among patients who died) over an average of 7.7 years of follow-up after initial revascularization. MI, Myocardial infarction; $C H F$, congestive heart failure. 